\title{
Correlation between reliability and weather scenario: In perspective of Bangladesh power system
}

\author{
Shohana Rahman Deeba, Nahid-Al-Masood \\ Department of Electrical and Electronic Engineering, Bangladesh University of Engineering and Technology, Dhaka-1000, Bangladesh
}

Email address:

shohanadeeba@yahoo.com(S. R. Deeba),nahid@eee.buet.ac.bd(Nahid-Al-Masood)

\section{To cite this article:}

Shohana Rahman Deeba, Nahid-Al-Masood. Correlation between Reliability and Weather Scenario: In Perspective of Bangladesh Power System. International Journal of Energy and Power Engineering. Vol. 2, No. 3, 2013, pp. 109-113. doi: 10.11648/j.ijepe.20130203.14

\begin{abstract}
This paper presents the correlation between the reliability and the weather scenario of Bangladesh Power System (BPS). Reliability of the power system is one of the major features of power quality. The variation of electrical demand above its base value is its common characteristic. The weather dependent variation of demand, especially where the weather is severe in nature, requires a significant reserve margin to ensure an acceptable level of reliability of the generation system. In Bangladesh, a significant difference in demands of winter and summer is generated due to weather variation. As a result the utility has to ensure an additional seasonal generation reserve capacity to maintain an acceptable level of reliability. This paper determines the correlation between the weather variables, namely temperature and relative humidity, and the reliability of Bangladesh Electricity Network. It also investigates the additional generation requirement during summer season to maintain an acceptable reliability level.
\end{abstract}

Keywords: Additional Generation, LOLP, Reliability, Recursive Algorithm, Relative Humidity, Temperature

\section{Introduction}

The basic function of a power system is to supply electrical energy to both large and small consumers as economically as possible and with an acceptable degree of reliability and quality. Reliability is the ability of a power system to provide service to consumers while maintaining the quality and price of electricity at an acceptable level. A significant portion of the electrical energy is consumed, especially in cold or hot countries, to mitigate the impact of weather on the daily life of human society [1]. In Bangladesh, industrial and commercial activities do not vary from winter to summer. Moreover, electrical devices are rarely used to get relieved from cold during winter. However, during summer electrical devices, fans and or air conditioners are invariably used. Therefore, the difference in demands of winter and summer is generated due to weather variation only. If the difference is significant then the utility has to ensure an additional seasonal generation reserve capacity to maintain an acceptable level of reliability.

A survey of literature reveals the fact that there has been a considerable activity in the development and application of reliability techniques in electric power systems. Two kinds of methodologies are adopted to consider the effect of fluctuating weather on power system reliability [2]-[5].
Adverse weather such as hurricanes can have significant impact on power system reliability. The effect of adverse weather on the reliability parameters of system components is addressed in [6] and [7].

Reliability issues are becoming increasingly important in modern distribution networks because of both social as well as economic implications. Several heuristic algorithms applied to find the optimal configuration of meshed distribution network is presented in [8]. Failures of reactive power sources in power system reliability evaluation are considered in [9]. To coordinate reliability and economy, an overall framework of optimal reliability algorithm for bulk power system based on total owning cost is proposed in [10]. Reliability enhancement of deregulated power systems considering demand-price elasticity is presented in [11]. In power system planning and operation procedures, bulk power system reliability assessment plays an important role. Bulk power system reliability assessment considering protection system hidden failures is illustrated in [12]. Power system reliability evaluation and quality assessment using fuzzy logic and genetic algorithm are presented in [13] and [14], respectively.

The change of temperature and humidity during summer and winter is high in Bangladesh. Therefore, its effect on the load patterns can not be passed over. However, during 
summer, the demand is significantly increased due to the high temperature. That is why BPS has to ensure an additional seasonal generation reserve capacity to maintain an acceptable level of reliability. This paper presents the correlation between the weather variables and the reliability of BPS. Reliability index, loss of load probability (LOLP) of BPS is evaluated using recursive algorithm for different months of last five years and its variation with the weather scenario of the country is investigated. It is observed that during winter season, reliability of BPS is relatively higher than that of summer season.

\section{Basic Data Analysis}

To identify the correlation between the weather variables and the reliability of BPS, the generation and the hourly demand of BPS of last five years is collected from its National Load Dispatch Centre (NLDC). The temperature and relative humidity data are collected from Bangladesh Meteorological department (BMD).

Before evaluating the monthly LOLP, the available data are analyzed. Fig. 1 and 2 depict the temperature and relative humidity variation of a typical summer and winter day, respectively.

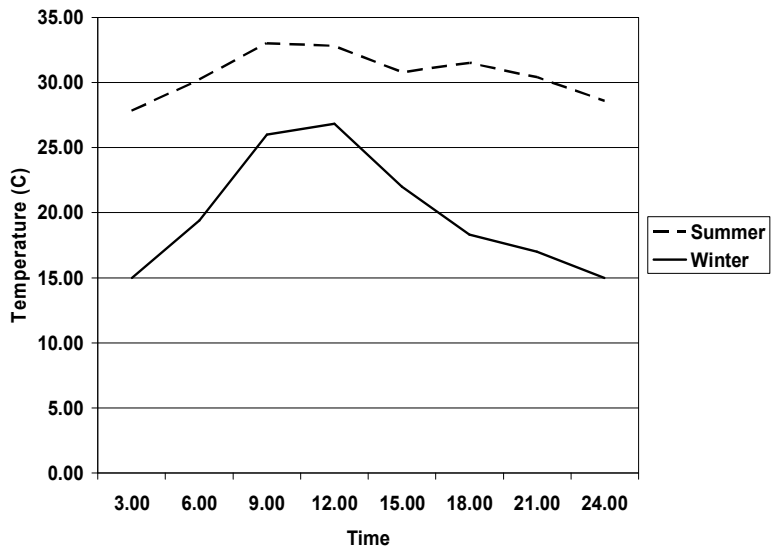

Fig 1. Temperature of a typical summer and winter day

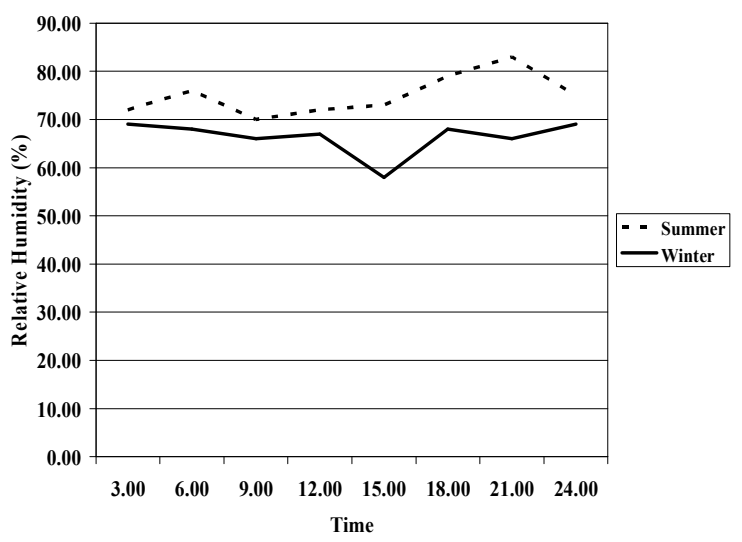

Fig 2. Relative humidity of a typical summer and winter day

In order to determine LOLP, the generating units and hourly loads have to be modeled .The following generator and load models are employed.

\subsection{Generator Model}

The simplest model for a generating unit for continuous operation is a "Run-Fail-Repair-Run" cycle that states that every generator has two states. They are- i) Unit availability and ii) Unit unavailability or forced outage rate (FOR). The unit availability means the long term probability that the generating unit will reside in on state and unit unavailability or FOR means the long term probability that the generating unit will reside in off state. Mathematically FOR can be defined as,

$$
\text { FOR }, u=\frac{\lambda}{\lambda+\mu}=\frac{r}{m+r}
$$

Where,

$\lambda=$ time to failure

$\mu=$ time to repair

$\mathrm{m}=$ mean time to failure $=\frac{1}{\lambda}$

$\mathrm{r}=$ mean time to repair $=\frac{1}{\mu}$

Unit availability of a generating unit can be defined as,

$$
\text { Unit availability, } a=\frac{\mu}{\lambda+\mu}=\frac{m}{m+r}=1-u
$$

Using the above model, each generator of BPS is exemplified by its rated capacity and FOR.

\subsection{Load Model}

In order to develop the load model of BPS, hourly loads of a particular month are divided into several groups. The occurrence of each group is then counted for that specific month. The probability of occurrence of any group is calculated as,

$$
P_{g}=\frac{N_{g}}{N_{t}}
$$

Where,

$\mathrm{Pg}=$ Probability of occurrence of a group

$\mathrm{Ng}=$ No. of occurring days of that group in observation period of 1 month

$\mathrm{Nt}=$ Total no. of days in observation period

Finally the average value of each group is taken and the corresponding probabilities reside for that average value of the load.

\section{The Recursive Algorithm}

The recursive expression for a state of X MW on forced outage after the addition of a generating unit of capacity $\mathrm{C}$ MW with FOR of $u$ is given by,

$$
p(X)=p^{\prime}(X)(1-u)+p^{\prime}(X-C) u
$$


Where, $\mathrm{p}(\mathrm{X})=$ Individual state probability.

If $X$ is less than $C$,

$$
p^{\prime}(X-C)=0
$$

After arranging all the states in ascending order, reserve of the power system is calculated using,

$$
\text { Reserve }=\text { Installed capacity-Load }
$$

LOLP of a particular load is then calculated using,

$$
L O L P_{\text {load }}=\text { probability }(\text { Outage }>\operatorname{Re} \text { serve })
$$

And finally, Total LOLP of the system is calculated using,

$$
L O L P=\sum\left(L O L P_{\text {load }}\right)(\text { pr.of load })
$$

Where,

Pr. of load = Occurrence probability of a particular load.

\section{Results and Discussions}

\subsection{Correlation between the Temperature and the System Reliability}

Using the recursive algorithm, the monthly LOLP of BPS of last five years is evaluated. Table I to V show the LOLP and corresponding monthly average temperature and relative humidity $(\mathrm{RH})$.

Table I. Monthly LOLP of Year 2011

\begin{tabular}{llll}
\hline Month & Avg. Temperature (0C) & Avg. RH (\%) & LOLP (\%) \\
\hline January & 18.50 & 69.41 & 0.91 \\
February & 24.40 & 65.69 & 1.15 \\
March & 27.20 & 54.33 & 1.48 \\
April & 28.90 & 68.32 & 2.33 \\
May & 29.50 & 73.12 & 2.54 \\
June & 29.70 & 82.00 & 3.02 \\
July & 30.25 & 80.43 & 3.75 \\
August & 29.20 & 77.68 & 3.15 \\
September & 28.90 & 81.17 & 3.20 \\
October & 26.40 & 76.66 & 1.57 \\
November & 23.90 & 68.70 & 1.02 \\
December & 19.80 & 69.65 & 1.01 \\
\hline
\end{tabular}

Table II. Monthly LOLP of Year 2010

\begin{tabular}{llll}
\hline Month & Avg. Temperature (0C) & Avg. RH (\%) & LOLP (\%) \\
\hline January & 18.92 & 68.25 & 0.94 \\
February & 24.86 & 64.12 & 1.20 \\
March & 27.42 & 58.70 & 1.50 \\
April & 28.58 & 68.97 & 2.35 \\
May & 29.07 & 74.01 & 2.60 \\
June & 29.08 & 83.51 & 3.10 \\
July & 29.48 & 79.85 & 3.80 \\
August & 29.14 & 78.25 & 3.20 \\
September & 29.20 & 80.74 & 3.30 \\
October & 27.94 & 75.82 & 1.60 \\
November & 24.26 & 66.37 & 1.10 \\
December & 20.62 & 70.29 & 1.05 \\
\hline
\end{tabular}

Table III: Monthly LOLP of Year 2009

\begin{tabular}{llll}
\hline Month & Avg. Temperature (0C) & Avg. RH (\%) & LOLP (\%) \\
\hline January & 18.20 & 69.85 & 0.89 \\
February & 24.10 & 65.28 & 1.12 \\
March & 26.40 & 55.87 & 1.47 \\
April & 28.20 & 69.30 & 2.32 \\
May & 29.70 & 75.25 & 2.47 \\
June & 30.10 & 82.53 & 3.01 \\
July & 29.90 & 80.28 & 3.12 \\
August & 30.10 & 77.28 & 3.58 \\
September & 28.85 & 81.27 & 3.15 \\
October & 26.20 & 74.95 & 1.52 \\
November & 22.15 & 65.54 & 1.01 \\
December & 18.90 & 69.24 & 0.99 \\
\hline
\end{tabular}

Table IV: Monthly LOLP of Year 2008

\begin{tabular}{llll}
\hline Month & Avg. Temperature (0C) & Avg. RH (\%) & LOLP (\%) \\
\hline January & 19.10 & 71.24 & 1.05 \\
February & 25.60 & 63.85 & 1.25 \\
March & 27.40 & 52.47 & 2.40 \\
April & 28.90 & 71.24 & 2.80 \\
May & 30.10 & 77.05 & 3.10 \\
June & 30.20 & 81.25 & 3.70 \\
July & 31.20 & 80.12 & 4.50 \\
August & 29.90 & 76.46 & 3.90 \\
September & 27.40 & 82.08 & 3.70 \\
October & 25.50 & 75.01 & 1.70 \\
November & 21.50 & 66.30 & 1.40 \\
December & 19.30 & 58.74 & 1.06 \\
\hline
\end{tabular}

Table V: Monthly LOLP of Year 2007

\begin{tabular}{llll}
\hline Month & Avg. Temperature (0C) & Avg. RH (\%) & LOLP (\%) \\
\hline January & 18.70 & 70.29 & 0.98 \\
February & 24.90 & 65.75 & 1.10 \\
March & 26.70 & 54.58 & 2.20 \\
April & 27.90 & 72.15 & 2.40 \\
May & 30.50 & 78.57 & 2.90 \\
June & 30.80 & 82.03 & 3.20 \\
July & 31.70 & 81.54 & 4.10 \\
August & 29.80 & 77.15 & 3.90 \\
September & 27.20 & 81.90 & 3.80 \\
October & 25.10 & 75.62 & 1.60 \\
November & 22.10 & 65.24 & 1.50 \\
December & 18.90 & 59.63 & 1.02 \\
\hline
\end{tabular}

The above results clearly reveal that in BPS, there is a strong correlation between the system reliability and the weather variables. In Bangladesh, summer spans from April to October when the temperature of the country is high. From November to March, the temperature of the country is relatively low and these months can be included in winter season.

From Table I to V, the average summer LOLP is $2.82 \%$ and that of winter is $1.21 \%$, which is shown in Fig. 3.

During summer, LOLP has a high value, that is, the reliability of the system is low and in winter, LOLP is relatively low, that is, the reliability of the system is high. During summer electrical devices, fans and or air conditioners are invariably used and as a consequence the system demand increases but due to limitation in resources, 
the generation can not be increased with the same rate as of demand. As a result the reliability of the system becomes low during summer period.

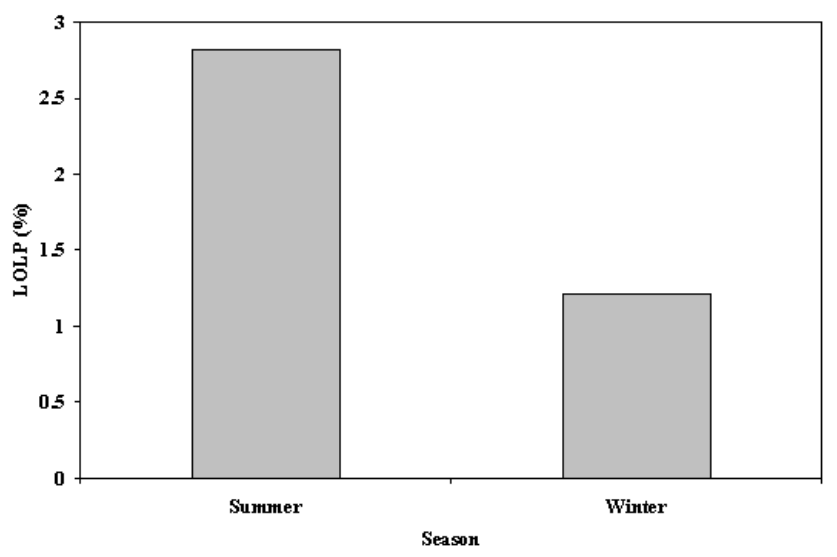

Fig 3. Average summer and winter LOLP

\subsection{Effect of the Additional Summer Generation on the System Reliability}

In order to improve the reliability of BPS during summer season, additional generation is added to the system and the system is simulated again. Table VI shows the simulation results.

It is observed from Table VI that due to $25 \%$ of additional generation during summer season, LOLP improves to $1.25 \%$ which is close to average winter LOLP of $1.21 \%$. If generation is increased further, system reliability will improve but cost due to additional generation will increase by a considerable amount. That is why $25 \%$ of additional generation is set as the maximum increment margin.

Table VI: Effect of Additional Summer Generation

\begin{tabular}{|c|c|c|}
\hline $\begin{array}{l}\text { Additional } \\
\text { generation }\end{array}$ & 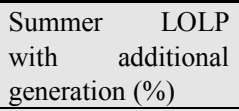 & $\begin{array}{l}\text { Summer LOLP with out } \\
\text { additional generation }(\%)\end{array}$ \\
\hline $5 \%$ & 2.62 & \multirow{5}{*}{2.82} \\
\hline $10 \%$ & 2.35 & \\
\hline $15 \%$ & 1.97 & \\
\hline $20 \%$ & 1.74 & \\
\hline $25 \%$ & 1.25 & \\
\hline
\end{tabular}

\section{Conclusion}

This paper presents the correlation between the weather variables and the reliability of BPS. It also investigates the additional generation requirement during summer season to improve the reliability of the system. In Bangladesh, electrical devices are rarely used to get relieved from cold during winter. But during summer electrical devices like fans and air conditioners are extremely used and as a result demand during summer period increase by a considerable margin that results in lower system reliability than that of winter.
The simulation results show that the average summer LOLP of BPS is $2.82 \%$ and that of winter is $1.21 \%$. Since the difference in demands of summer and winter is significant, BPS has to ensure an additional seasonal generation reserve capacity to maintain an acceptable level of reliability. The results clearly reveal that BPS requires an arrangement of additional $25 \%$ of generation capacity to ensure an acceptable level of reliability during summer.

\section{References}

[1] S. Ruzic, A. Vuckovic, and N. Nikolic, "Weather Sensitive Method for Short Term Load Forecasting in Electric Power Utility of Serbia”, IEEE Transactions on Power Systems, vol.18. no. 4, pp. 158-1586, Nov. 2003.

[2] R. Billinton , and G. Singh, "Application of Adverse and Extreme Adverse Weather: Modeling in Transmission and Distribution System Reliability Evaluation," in Proc. Inst. Elect. Eng., Gen., Transm., Distrib., Jan. 2006, vol. 153, no. 1, pp. $115-120$.

[3] C. Dichirico, and C. Singh, "Reliability Analysis of Transmission Lines with Common Mode Failures When Repair Times are Arbitrarily Distributed," IEEE Transactions on Power Systems, vol. 3, no. 3, pp. 1012-1019, Aug. 1988.

[4] R. Billinton, and W. Li, "A Novel Method for Incorporating Weather Effects in Composite System Adequacy Evaluation," IEEE Transactions on Power Systems, vol. 6, no. 3, pp. 1154-1160, Aug. 1991.

[5] M. R. Bhuiyan and R. N. Allan, "Inclusion of Weather Effects in Composite System Reliability Evaluation Using Sequential Simulation,” in Proc. Inst. Elect. Eng., Gen., Transm., Distrib., Nov. 1994, vol. 141, no. 6, pp. 575-584.

[6] R. A. Davidson, H. Liu, I. K. Sarpong, P. Sparks, and D. V. Rosowsky, "Electric Power Distribution System Performance in Carolina Hurricanes," Nat. Haz. Rev., vol. 4, no. 1, pp. 36-45, Feb. 2003.

[7] H. Liu, R. A. Davidson, D. V. Rosowsky, and J. R. Stedinger, "Negative Binomial Regression of Electric Power Outages in Hurricanes," Journal of Infrastruct. System, vol. 11, no. 4, pp. 258-267, Dec. 2005.

[8] V. Dumbrava, C. Lazaroiu, C. Roscia, and D. Zaninelli, "Expansion Planning and Reliability Evaluation of Distribution Networks By Heuristic Algorithms", in Proc 10th International Conference on: Environment and Electrical Engineering (EEEIC), May 2011, pp. 1-4.

[9] W. Qin, P. Wang, X. Han, and X. Du, "Reactive Power Aspects in Reliability Assessment of Power Systems", IEEE Transactions on Power Systems, vol. 26, no. 1, pp. 85-92, Feb. 2011.

[10] S. Yunting, W. Quan, and Z. Wenjuan, "Optimal Reliability 
Evaluation Method of Bulk Power System Based on IGA”, in ProcInternational Conference on Sustainable Power Generation and Supply, Apr. 2009, pp. 1-7.

[11] L.Goel, Q. Wu, P. Wang, and Y. Ding, "Reliability Enhancement of Deregulated Power Systems Considering Demand-Price Elasticity", in Proc 7th International Power Engineering Conference, Nov. 2005, vol. 2, pp. 934-938.

[12] F. Yang, A. P. S. Meliopoulos, G. J. Cokkinides and Q. B. Dam, "Bulk Power System Reliability Assessment Considering Protection System Hidden Failures”, presented at the Bulk Power System Dynamics and Control Symposium, pp. 1-8, Aug. 2007.

[13] M.A Farahat, and B. M. Al-Shammari, "Power System Reliability Evaluation and Quality Assessment by Fuzzy Logic Technique", in Proc. Inst. Universities Power Engineering Conference, Sept. 2004 vol. 1, pp. 478-483.

[14] R.C. Green, L. Wang, and C. Singh, "State Space Pruning for Power System Reliability Evaluation Using Genetic Algorithms", presented at the IEEE Power and Energy Society General Meeting, pp. 1-6, July 2010. 